\section{Cureus}

Received 03/24/2015

Review began 03/25/2015

Review ended 09/26/2015

Published 10/12/2015

\section{(c) Copyright 2015}

Towers et al. This is an open access article distributed under the terms of the Creative Commons Attribution License CC-BY 3.0., which permits unrestricted use, distribution, and reproduction in any medium, provided the original author and source are credited.

\title{
Stand-alone LLIF Lateral Cage Migration: A Case Report
}

\author{
Wendy S. Towers $^{1}$, Khalid H. Kurtom ${ }^{1}$ \\ 1. Neurosurgery, University of Maryland Shore Regional Health
}

$\square$ Corresponding author: Wendy S. Towers, wtowers@shorehealth.org

Disclosures can be found in Additional Information at the end of the article

\section{Abstract}

Lateral approaches to the lumbar disc space have become popular in recent years with very few reported complications. We report on a rare case of a stand-alone cage migration.

A 77-year-old female presented with a right L2-3 radiculopathy that was refractory to maximum medical management. This was secondary to foraminal compression at L2-3 and L34 due to degenerative disc disease and levoscoliosis, as well as Grade 1 spondylolisthesis at both levels. A left-sided approach lateral lumbar interbody fusion was performed at L2-3 and L3-4 using a lordotic polyetheretherketone (PEEK) graft (50 mm length $\mathrm{x} 18 \mathrm{~mm}$ width $\mathrm{x} 9 \mathrm{~mm}$ height) packed with demineralized bone matrix (DBM). A contralateral release of the annulus fibrosis was performed during the decompression prior to graft insertion. Postoperative anteroposterior and lateral x-ray imaging confirmed good position of interbody grafts, correction of scoliosis as well as spondylolisthesis, and restoration of disc height achieving foraminal indirect decompression. A routine postoperative x-ray at three months demonstrated asymptomatic ipsilateral cage migration at the L2-3 level with evidence of arthrodesis in the disc space. This was managed conservatively without further surgical intervention.

Placement of a lateral plate or interbody intradiscal plating system in patients with scoliosis and significant coronal deformity is an option that can be considered to prevent this rare LLIF complication. Moreover, asymptomatic cage migration may be conservatively managed without reoperation.

Categories: Neurosurgery

Keywords: cage migration, lateral lumbar fusion, minimally invasive spine surgery

\section{Introduction}

The minimally invasive transpsoas lateral lumbar interbody fusion (LLIF) was first described by Ozgur, et al. [1] in 2006. Since then, it has become a valuable option for patients with degenerative disc disease, spondylolisthesis, foraminal stenosis, tumor, and trauma [1-4]. Stand-alone LLIF is a minimally invasive transpsoas approach to achieve indirect decompression of the neural elements while restoring disc height and spinal alignment without other fixation measures, such as pedicle screws or lateral plate. The LLIF permits thorough disc removal and preparation of the graft bed. Indirect decompression is achieved by laterally placing an interbody graft of polyetheretherketone (PEEK) while maintaining biomechanical ligamental structures, namely the anterior longitudinal ligament and annulus, both restricting motion [1]. The implant also spans the apophyseal ring, which avoids cancellous bone. and therefore, in theory, inhibits subsidence [5-6]. 


\section{Cureus}

While avoiding major complications encountered by the anterior approach, such as injury to the retroperitoneal structures, great vessels and the sympathetic plexus, the LLIF has its own unique complications. The neural structures of the lumbosacral plexus can be injured [1]. Electromyogram (EMG) neuromonitoring is used to aid in the detection and avoidance of these neural structures. Sensory neural structures, such as the lateral femoral cutaneous nerve, cannot be identified with EMG; therefore, visual inspection of the surgical site is also important to avoid injuring this nerve [7]. A rare complication of the lateral interbody fusion is cage migration. It has been previously reported once in the literature, to our knowledge, in a patient that became symptomatic, necessitating a revision [8]. We report another case of stand-alone LLIF cage migration, in this instance, in an asymptomatic patient who was managed conservatively with observation.

\section{Case Presentation}

Informed patient consent was obtained prior to treatment. With the patient's permission, we report on a case of a 77-year-old female who presented with right L2-3 radiculopathy that was refractory to maximum medical management. This was secondary to foraminal compression at L2-3 and L3-4 due to degenerative disc disease, levoscoliosis, as well as grade 1 spondylolisthesis at both levels (Figures 1,2).
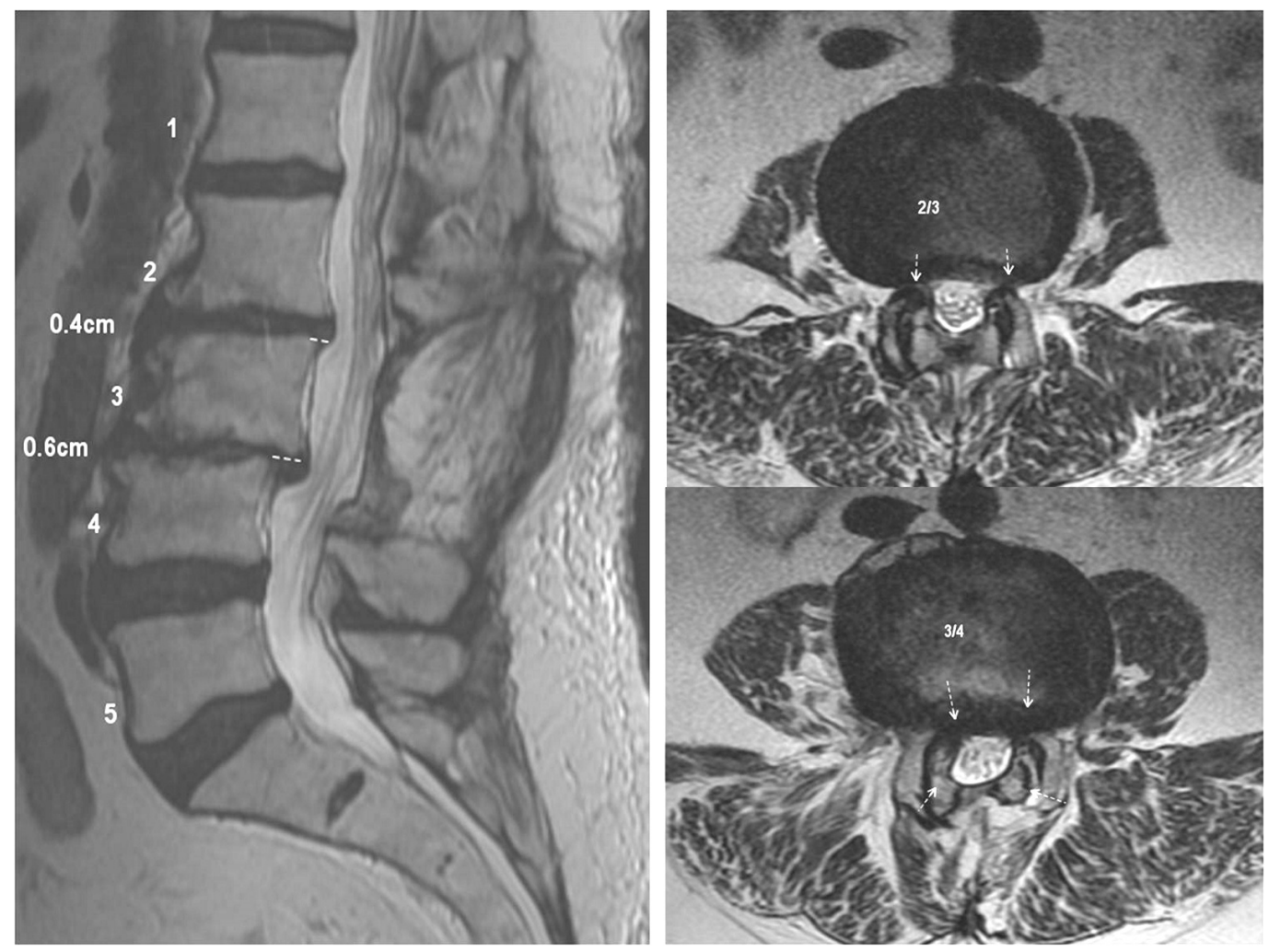

FIGURE 1: Preoperative MRI

L2-3 and L3-4 degenerative disc disease, levoscoliosis, Grade 1 spondylolisthesis 


\section{Cureus}

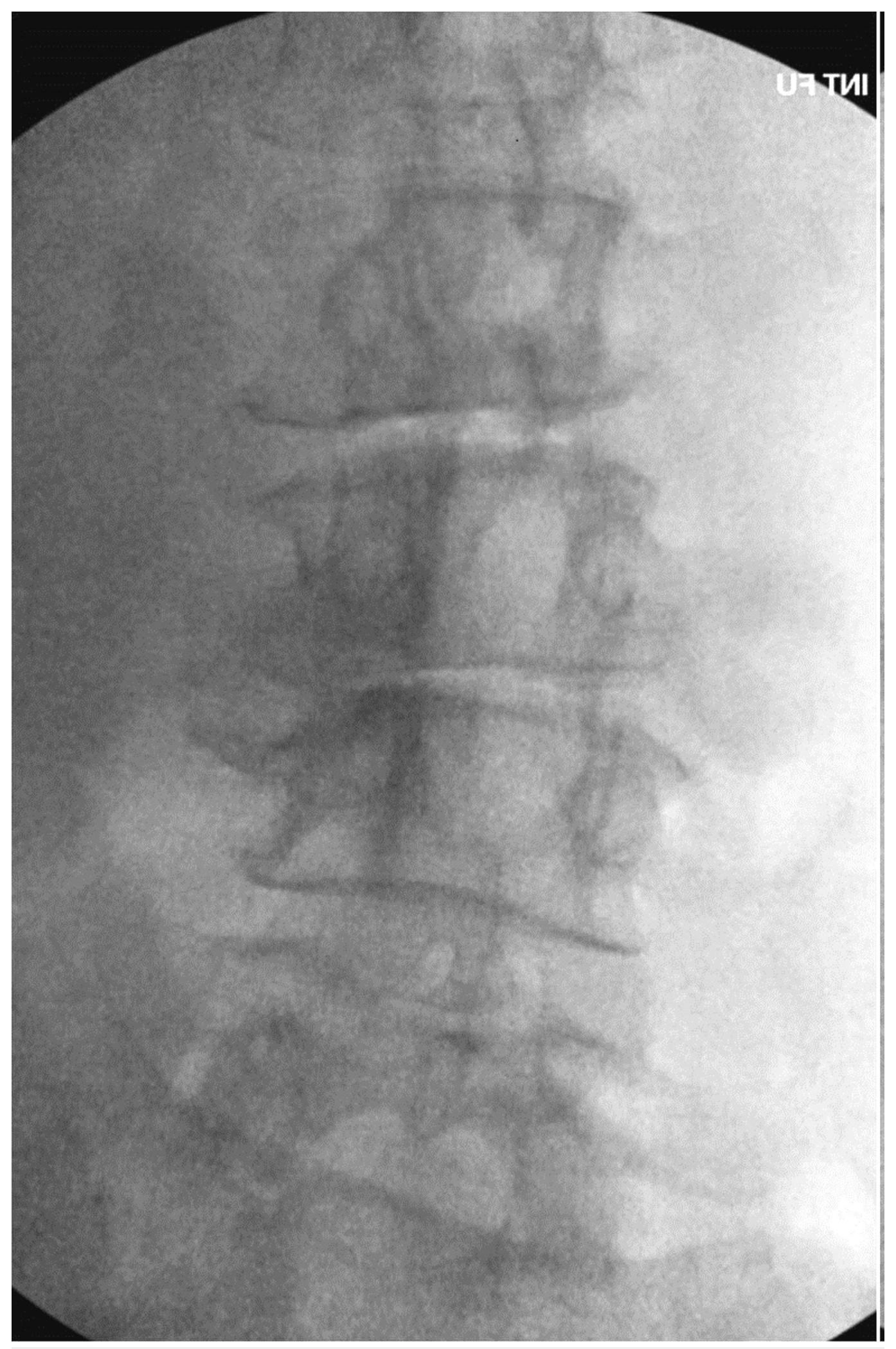

FIGURE 2: Preoperative x-ray

Levoscoliosis L2-3, L3-4

Given the patient's prior history of posterior decompressive laminectomy, it was felt that the 


\section{Cureus}

best approach would be a minimally invasive lateral approach to obtain indirect decompression of the foramina as well as correct her spinal deformity. This will achieve the goals of decompression and fusion as well as deformity correction while avoiding the risk of operating through scar tissue. A retroperitoneal transpsoas approach was used to expose the disc spaces from the patient's left side, initially at L3-4 followed by L2-3, using anteroposterior and lateral fluoroscopy imaging as well as neuromonitoring. Complete discectomy was performed with the release of the contralateral annulus fibrosis followed by the interbody fusion. A lordotic PEEK graft was used at each level, $50 \mathrm{~mm}$ length x $18 \mathrm{~mm}$ width $\mathrm{x} 9 \mathrm{~mm}$ height, packed with demineralized bone matrix (DBM). Postoperative anteroposterior and lateral $\mathrm{x}$-ray imaging confirmed good position of interbody grafts, correction of scoliosis as well as spondylolisthesis, and restoration of disc height achieving satisfactory foraminal indirect decompression (Figure 3).
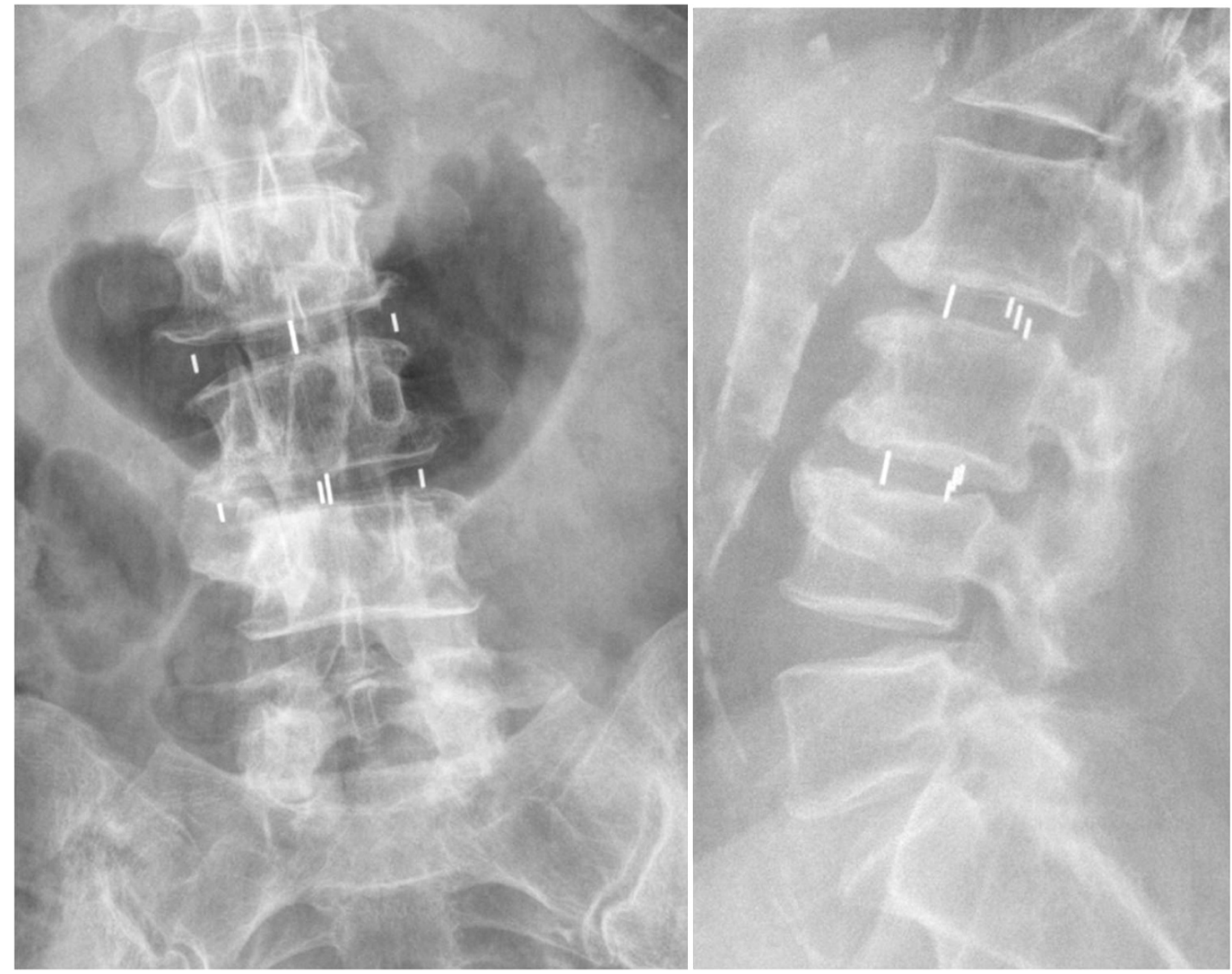

\section{FIGURE 3: Immediate postoperative A/P and lateral fluoroscopy}

Cage position(s) in good A/P and lateral alignment with correction of scoliosis, spondylolisthesis, and restoration of disc height

A routine postoperative $\mathrm{x}$-ray at three months demonstrated lateral cage migration on the left side at the L2-3 level with evidence of arthrodesis in the disc space (Figure 4). 


\section{Cureus}
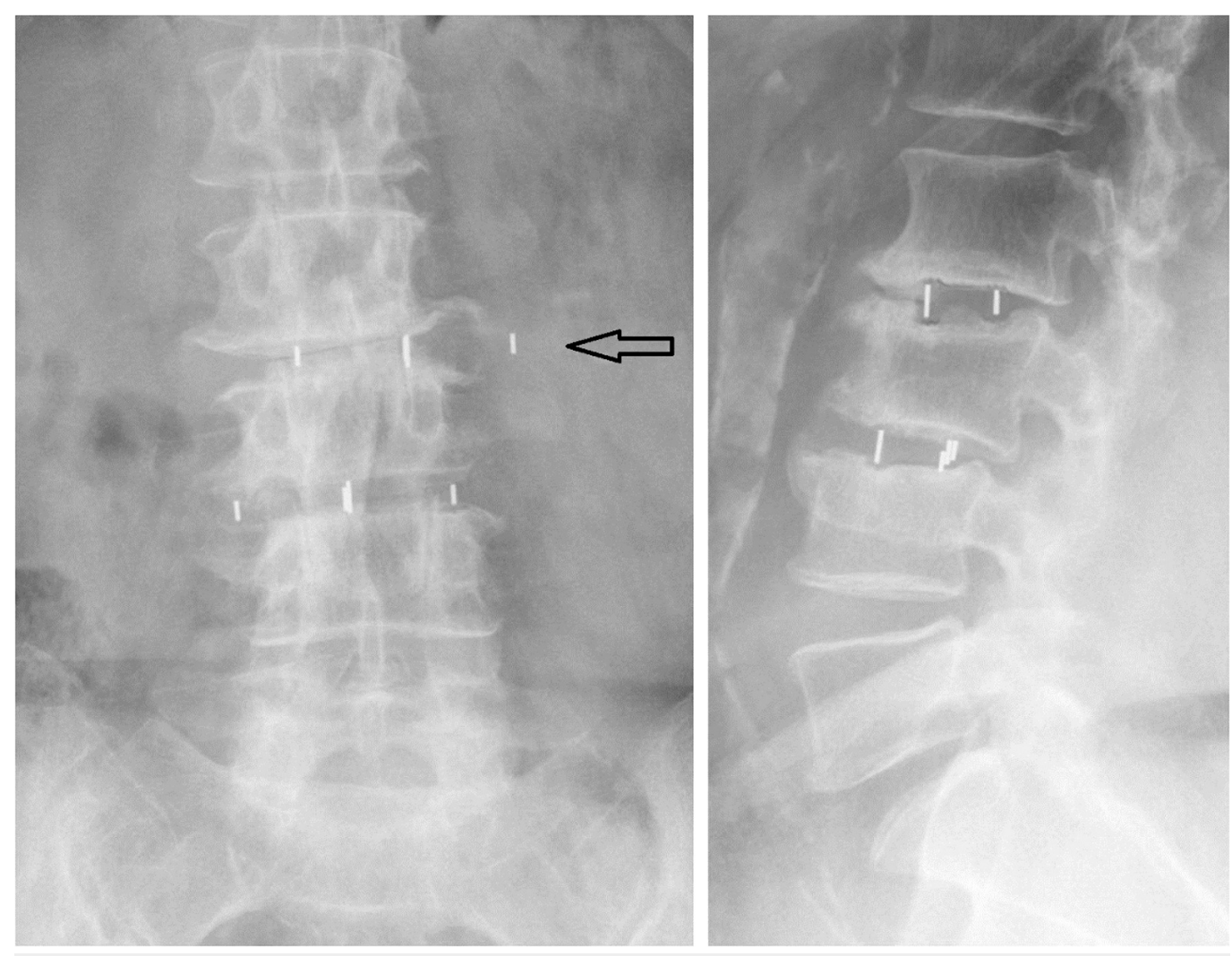

\section{FIGURE 4: Three month postoperative x-ray}

Lateral cage migration at L2-3

The patient was asymptomatic. Therefore, a decision was made to continue conservative management without surgical revision. She remained asymptomatic and follow-up imaging at one year demonstrated completed fusion without further migration of the interbody graft at L23.

\section{Discussion}

Symptomatic adjacent level degeneration post lumbar spinal fusion occurs at a rate of $2 \%-3 \%$ per year as reported by Radcliff et al. [9]. Due to this rate of adjacent level disease progression and the increased risks associated with posterior re-operation, the lateral lumbar approach has become a valuable option especially for rostral adjacent segment degeneration above L4-5 [10]. Patients with degenerative spinal deformity or compression of the neural elements and prior posterior lumbar surgery also benefit from this approach with indirect decompression and restoration of normal spinal alignment. The LLIF achieves anterolisthesis reduction, disc height restoration with foraminal decompression, and spinal fusion without complications associated with direct anterior fusion.

Minimally invasive LLIF, also referred to as extreme lateral interbody fusion (XLIF) or direct lateral interbody fusion (DLIF), can be performed as a stand-alone interbody fusion with posterior fixation or with lateral plate fixation. The anterior spine is approached through a retroperitoneal transpsoas incision as is described in various techniques with minor differences, hence, the procedure name variations $[1,8,11-15]$. The LLIF approach has its own unique complications. Technique directed complications are most often related to nerve injury as the retractor is placed through the psoas by a muscle-splitting technique [7, 16-18]. Neural 
complications are reported in 19-67\% of patients and are described as anterior thigh pain, paresthesia, and dysesthesia as well as hip flexor weakness [19-21].

Femoral neuropraxia occurs most frequently when the level of spinal fusion is at the L4-5 disc space. Several studies have shown that the femoral nerve can lie directly over the center of the disc space at the L4- 5 disc level, which increases its chance for injury; this can be devastating [22-25]. Grimm, et al. [16] suggested that limiting the retractor time at L4-5 may decrease the incidence of femoral nerve neuropraxia; however, they did not determine a safe timeframe. Davis, et al. [23] hypothesized that traction and compression of the femoral nerve against the L5 transverse process may not elicit a warning by neuromonitoring. Rodgers [18] determined that administering $10 \mathrm{mg}$ of dexamethasone prior to incision for patients undergoing LLIF at the L4-5 level had zero neural deficits. Despite all attempts to reduce the risk of femoral neuropraxia during LLIF approach, this complication poses a concern for most surgeons performing this procedure.

A mode of failure of the implant in LLIF as well as other fusion techniques is subsidence. Le, et al. [26] studied 140 LLIF patients with a reported subsidence rate of $14.3 \%$ as demonstrated in anteroposterior and lateral radiographs. They defined subsidence as any compromise of the end plate. With this definition, they demonstrated a statistically significant positive correlation of subsidence with increasing construct length, with a $10.3 \%$ rate for one-level and up to $50 \%$ for four-level constructs. The rate of subsidence was only $1.9 \%$ with the $22 \mathrm{~mm}$ wide construct as opposed to $14.1 \%$ with the $18 \mathrm{~mm}$ wide construct. Of note, seven out 140 patients underwent stand-alone fusion with $0 \%$ subsidence in that group.

Our patient presented with scoliosis as well as spondylolisthesis, so an argument could be made to use supplemental posterior pedicle screw or lateral plate fixation in addition to the interbody cage. Marchi, et al. [2] studied 52 consecutive patients who underwent stand-alone LLIF for the treatment of low-grade spondylolisthesis with a 24-month follow-up. Postoperative complications were psoas weakness (19.2\%), anterior thigh numbness (9.6\%) that resolved within six weeks, and a $17 \%$ subsidence rate. There was no report of cage migration. Isaacs, et al. [17] reported perioperative outcomes and complications in a prospective, non-randomized multicenter study of extreme lateral interbody fusion for the treatment of adult degenerative scoliosis. They reviewed 107 cases with 18.7\% patients receiving stand-alone XLIF. Of all the patients, 33.3\% had some evidence of weakness after surgery with $6.5 \%$ not resolved within six months. They did not report subsidence rates. Complications did not include cage migration.

Lateral graft migration is a rare complication of LLIF, with a single reported case by Daffner and Wang [8]. They described a 50\% laterally migrated interbody cage after an XLIF at L3-4 with supplemented posterior pedicle fixation. The patient was symptomatic. A revision was successfully completed with complete resolution of symptoms. They suspected that the maximal compression across the interbody graft was not achieved due to inadequate posterior forces. Another theory proposed is the contralateral annulus was inadequately released, and therefore, the residual coronal imbalance increased asymmetric pressure. The authors concluded a lateral plate should be utilized as reinforcement in patients that have a significant coronal abnormality or lateral listhesis adjacent to prior fusions in order to prevent graft migration. The proposed theories do not account for the complication in our patient since the contralateral annulus was fully released during the operation, resulting in the complete restoration of coronal imbalance post-graft placement. We do agree that a plating system could have prevented the complication encountered in our patient.

An intact anterior longitudinal ligament and posterior longitudinal ligament will prevent anterior-posterior graft migration, theoretically obviating the need for posterior fixation. Movement in flexion and extension should not destabilize the graft if both of these 
ligaments remain intact. On the other hand, proper technique during LLIF operation necessitates releasing both lateral annuli, so graft migration laterally is not restricted with lateral bending. This is remedied by placement of a lateral plate. Another option is to use an interbody with intradiscal plating system, which is especially useful in patients with prior fusion in adjacent levels.

\section{Conclusions}

Lateral cage migration in LLIF is a rare complication. Asymptomatic lateral cage migrations can be conservatively managed without potentially risky revision procedures. Placement of a lateral plate or interbody intradiscal plating system in patients with scoliosis and significant coronal deformity is an option that can be considered to prevent this rare LLIF complication.

\section{Additional Information \\ Disclosures}

Human subjects: Consent was obtained by all participants in this study. Conflicts of interest: In compliance with the ICMJE uniform disclosure form, all authors declare the following: Payment/services info: All authors have declared that no financial support was received from any organization for the submitted work. Financial relationships: All authors have declared that they have no financial relationships at present or within the previous three years with any organizations that might have an interest in the submitted work. Other relationships: All authors have declared that there are no other relationships or activities that could appear to have influenced the submitted work.

\section{References}

1. Ozgur BM, Aryan HE, Pimenta L, Taylor WR: Extreme Lateral Interbody Fusion (XLIF): a novel surgical technique for anterior lumbar interbody fusion. Spine J. 2006, 6:435-43. 10.1016/j.spinee.2005.08.012

2. Marchi L, Abdala N, Oliveira L, Amaral R, Coutinho E, Pimenta L: Stand-alone lateral interbody fusion for the treatment of low-grade degenerative spondylolisthesis. ScientificWorldJournal. 2012, 2012:456346. 10.1100/2012/456346

3. Marchi L, Oliveira L, Amaral R, Castro C, Coutinho T, Coutinho E, Pimenta L: Lateral interbody fusion for treatment of discogenic low back pain: minimally invasive surgical techniques. Adv Orthop. 2012, 2012:282068. 10.1155/2012/282068

4. Karikari IO, Nimjee SM, Hardin CA, Hughes BD, Hodges TR, Mehta AI, Choi J, Brown CR, Isaacs RE: Extreme lateral interbody fusion approach for isolated thoracic and thoracolumbar spine diseases: initial clinical experience and early outcomes. J Spinal Disord Tech. 2011, 24:368-75. 10.1097/BSD.0b013e3181ffefd2

5. Cappuccino A, Cornwall GB, Turner AW, Fogel GR, Duong HT, Kim KD, Brodke DS: Biomechanical analysis and review of lateral lumbar fusion constructs . Spine. 2010, 35:S36167. 10.1097/BRS.0b013e318202308b

6. Oliveira L, Marchi L, Coutinho E, Pimenta L: A radiographic assessment of the ability of the extreme lateral interbody fusion procedure to indirectly decompress the neural elements. Spine. 2010, 35:S331-37. 10.1097/BRS.0b013e3182022db0

7. Knight RQ, Schwaegler P, Hanscom D, Roh J: Direct lateral lumbar interbody fusion for degenerative conditions: early complication profile. J Spinal Disord Tech. 2009, 22:34-37. 10.1097/BSD.0b013e3181679b8a

8. Daffner SD, Wang JC: Migrated XLIF cage: case report and discussion of surgical technique . Orthopedics. 2010, 33:518. 10.3928/01477447-20100526-21

9. Radcliff KE, Kepler CK, Jakoi A, Sidhu GS, Rihn J, Vaccaro AR, Albert TJ, Hilibrand AS: Adjacent segment disease in the lumbar spine following different treatment interventions . Spine J. 2013, 13:1339-49. 10.1016/j.spinee.2013.03.020

10. Wang MY, Vasudevan R, Mindea SA. : Minimally invasive lateral interbody fusion for the treatment of rostral adjacent-segment lumbar degenerative stenosis without supplemental 
pedicle screw fixation. J Neurosurg Spine. 2014, 21:861-66. 10.3171/2014.8.SPINE13841

11. Eck JC, Hodges S, Humphreys SC: Minimally invasive lumbar spinal fusion . J Am Acad Orthop Surg. 2007, 15:321-29.

12. Madhok R, Kanter AS: Extreme-lateral, minimally invasive, transpsoas approach for the treatment of far-lateral lumbar disc herniation: Report of 2 cases. J Neurosurg Spine. 2010, 12:347-50. 10.3171/2009.10.SPINE08932

13. Patel AA, Brodke DS, Pimenta L, Bono CM, Hilibrand AS, Harrop JS, Riew KD, Youssef JA, Vaccaro AR: Revision strategies in lumbar total disc arthroplasty. Spine. 2008, 33:1276-83. 10.1097/BRS.0b013e3181714a1d

14. Pimenta L, Diaz RC, Guerrero LG: Charité lumbar artificial disc retrieval: use of a lateral minimally invasive technique. Technical note. J Neurosurg Spine. 2006, 5:556-61. 10.3171/spi.2006.5.6.556

15. Shen FH, Samartzis D, Khanna AJ, Anderson DG: Minimally invasive techniques for lumbar interbody fusions. Orthop Clin North Am. 2007, 38:373-86. 10.1016/j.ocl.2007.04.002

16. Grimm BD, Leas DP, Poletti SC, Johnson DR 2nd: Postoperative complications within the first year after extreme lateral interbody fusion: experience of the first 108 patients . J Spinal Disord Tech. 2014, [E-pub ahead of print]. Accessed: March 2, 2015: http://journals.lww.com/jspinaldisorders/pages/articleviewer.aspx? year=9000 \&issue $=00000$ \&article=99227 \&type=abstract. $10.1097 /$ BSD .0000000000000121

17. Isaacs RE, Hyde J, Goodrich JA, Rodgers WB, Phillips FM: A prospective, nonrandomized, multicenter evaluation of extreme lateral interbody fusion for the treatment of adult degenerative scoliosis: perioperative outcomes and complications. Spine. 2010, 35:S322-30. 10.1097/BRS.0b013e3182022e04

18. Rodgers WB, Gerber EJ, Patterson J: Intraoperative and early postoperative complications in extreme lateral interbody fusion: an analysis of 600 cases. Spine. 2011, 36:26-32. 10.1097/BRS.0b013e3181e1040a

19. Cummock MD, Vanni S, Levi AD, Yu Y, Wang MY: An analysis of postoperative thigh symptoms after minimally invasive transpsoas lumbar interbody fusion. J Neurosurg Spine. 2011, 15:11-18. 10.3171/2011.2.SPINE10374

20. Le TV, Burkett CJ, Deukmedjian AR, Uribe JS: Postoperative lumbar plexus injury after lumbar retroperitoneal transpsoas minimally invasive lateral interbody fusion. Spine. 2013, 38:E1320. 10.1097/BRS.0b013e318278417c

21. Moller DJ, Slimack NP, Acosta FL Jr, Koski TR, Fessler RG, Liu JC: Minimally invasive lateral lumbar interbody fusion and transpsoas approach-related morbidity. Neurosurg Focus. 2011, 31:E4. 10.3171/2011.7.FOCUS11137

22. Benglis DM, Vanni S, Levi AD: An anatomical study of the lumbosacral plexus as related to the minimally invasive transpsoas approach to the lumbar spine. J Neurosurg Spine. 2009, 10:139-44. 10.3171/2008.10.SPI08479

23. Davis TT, Bae HW, Mok JM, Rasouli A, Delamarter RB: Lumbar plexus anatomy within the psoas muscle: implications for the transpsoas lateral approach to the L4-L5 disc. J Bone Joint Surg AM. 2011, 93:1482-87. 10.2106/JBJS.J.00962

24. Park DK, Lee MJ, Lin EL, Singh K, An HS, Phillips FM: The relationship of intrapsoas nerves during a transpsoas approach to the lumbar spine: anatomic study. J Spinal Disord Tech. 2010, 23:223-28. 10.1097/BSD.0b013e3181a9d540

25. Uribe JS, Arredondo N, Dakwar E, Vale FL: Defining the safe working zones using the minimally invasive lateral retroperitoneal transpsoas approach: an anatomic study. J Neurosurg Spine. 2010, 13:260-66. 10.3171/2010.3.SPINE09766

26. Le TV, Baaj AA, Dakwar E, Burkett CJ, Murray G, Smith DA, Uribe JS.: Subsidence of polyetheretherketone intervertebral cages in minimally invasive lateral retroperitoneal transpsoas lumbar interbody fusion. Spine. 2012, 37:1268-73. 10.1097/BRS.0b013e3182458b2f 